\title{
ON EMBEDDINGS BETWEEN CLASSICAL LORENTZ SPACES
}

\author{
M. CARro, L. Pick, J. Soria And V. D. Stepanov
}

\begin{abstract}
Let $p \in(0, \infty)$, let $v$ be a weight on $(0, \infty)$ and let $\Lambda^{p}(v)$ be the classical Lorentz space, determined by the norm $\|f\|_{\Lambda^{p}(v)}:=\left(\int_{0}^{\infty}\left(f^{*}(t)\right)^{p} v(t) d t\right)^{1 / p}$. When $p \in(1, \infty)$, this space is known to be a Banach space if and only if $v$ is non-increasing, while it is only equivalent to a Banach space if and only if $\Lambda^{p}(v)=\Gamma^{p}(v)$, where $\|f\|_{\Gamma^{p}(v)}:=\left(\int_{0}^{\infty}\left(f^{* *}(t)\right)^{p} v(t) d t\right)^{1 / p}$. We may thus conclude that, for $p \in(1, \infty)$, the space $\Lambda^{p}(v)$ is equivalent to a Banach space if and only if the norm of a function $f$ in it can be expressed in terms of $f^{* *}$. We study the question whether an analogous assertion holds when $p=1$. Motivated by this problem, we consider general embeddings between four types of classical and weak Lorentz spaces, namely, $\Lambda^{p}(v)$, $\Lambda^{p, \infty}(v), \Gamma^{p}(v), \Gamma^{p, \infty}(v)$, where $\Lambda^{p, \infty}(v)$ and $\Gamma^{p, \infty}(v)$ are certain weak analogues of the spaces $\Lambda^{p}(v)$ and $\Gamma^{p}(v)$, respectively. We present a unified approach to these embeddings, based on rearrangement techniques. We survey all the known results and prove new ones. Our main results concern the embedding $\Gamma^{p, \infty}(v) \hookrightarrow \Lambda^{q}(w)$ which had not been characterized so far. We apply our results to the characterization of associate spaces of classical and weak Lorentz spaces and we give a characterization of fundamental functions for which the endpoint Lorentz space and the endpoint Marcinkiewicz space coincide.
\end{abstract}

Mathematics subject classification (2000): 46E30, $26 \mathrm{D} 15$.

Key words and phrases: Classical Lorentz spaces, continuous embeddings, weighted inequalities for non-increasing functions.

\section{REFERENCES}

[1] M. ARIÑo AND B. MUCKenHoupt, Maximal functions on classical Lorentz spaces and Hardy's inequality with weights for nonincreasing functions, Trans. Amer. Math. Soc. 320 (1990), 727-735.

[2] S. BARZA, L. E. PERSSON AND J. SORIA, Sharp weighted multidimensional integral inequalities for monotone functions, Math. Nachr 210 (2000), 43-58.

[3] C. BennetT AND K. Rudnick, On Lorentz-Zygmund spaces, Dissert. Math. 175 (1980), 1-72.

[4] C. BenNetT AND R. Sharpley, Interpolation of Operators, Academic Press, Princeton, 1988.

[5] J. Bergh AND J. LÖFSTRÖM, Interpolation Spaces. An Introduction, Springer-Verlag, Berlin, 1976.

[6] D. W. BoYD, The Hilbert transform on rearrangement-invariant spaces, Canad. J. Math. 19 (1967), 599-616.

[7] M. CARRO, A. GARCÍA DEL AMO AND J. SORIA, Weak-type weights and normable Lorentz spaces, Proc. Amer. Math. Soc. 124 (1996), 849-857.

[8] M. CARro AND J. Soria, Weighted Lorentz spaces and the Hardy operator, J. Funct. Analysis 112 (1993), 480-494.

[9] M. CARRO AND J. SORIA, Boundedness of some integral operators, Canad. J. Math. 45 (1993), 1155-1166.

[10] M. CARRO AND J. SORIA, The Hardy-Littlewood maximal function and weighted Lorentz spaces, J. London Math. Soc. 55 (1997), 146-158.

[11] M. L. GoL'DMAN, On integral inequalities on a cone of functions with monotonicity properties, Soviet Math. Dokl. 44 (1992), 581-587. 
[12] M. L. GoL'DMAN, On integral inequalities on the set of functions with some properties of monotonicity, Function spaces, Differential Operators and Nonlinear Analysis, Teubner Texte Zur Math. 133, Leipzig, 1993, pp. 274-279.

[13] M. L. Gol'dman, H. P. Heinig And V. D. Stepanov, On the principle of duality in Lorentz spaces, Canad. J. Math. 48 (1996), 959-979.

[14] I. HalPERIN, Function spaces, Canad. J. Math. 5 (1953), 273-288.

[15] H. P. HEINIG AND L. MALIGRANDA, Weighted inequalities for monotone and concave functions, Studia Math. 116 (1995), 133-165.

[16] S. LAI, Weighted norm inequalities for general operators on monotone functions, Trans. Amer. Math. Soc. 340 (1993), 811-836.

[17] G. G. LoRENTZ, On the theory of spaces $\Lambda$, Pacific J. Math. 1 (1951), 411-429.

[18] C. J. NEUGEBAUER, Weighted norm inequalities for averaging operators of monotone functions, Publ. Math. 35 (1991), 429-447.

[19] E. SAWYER, Boundedness of classical operators on classical Lorentz spaces, Studia Math. 96 (1990), $145-158$.

[20] G. Sinnamon, Spaces defined by level functions and their duals, Studia Math. 111 (1994), 19-52.

[21] G. Sinnamon And V. D. Stepanov, The weighted Hardy inequality: new proofs and the case $p=1$, J. London Math. Soc. 54 (1996), 89-101.

[22] J. SORIA, Lorentz spaces of weak-type, Quart. J. Math. Oxford 49 (1998), 93-103.

[23] V. D. Stepanov, The weighted Hardy's inequality for nonincreasing functions, Trans. Amer. Math. Soc. 338 (1993), 173-186.

[24] V. D. STEPANOV, Integral operators on the cone of monotone functions, J. London Math. Soc. 48 (1993), 465-487.

[25] V. D. STEPANOV, On integral operators on the cone of monotone functions, and on imbeddings of Lorentz spaces, Soviet Math. Dokl. 43 (1991), 620-623. 